\title{
Correction to: In the presence of red light, cucumber and possibly other host plants lose their attractability to the melon thrips Thrips palmi (Thysanoptera: Thripidae)
}

\author{
Mika Murata $^{1} \cdot$ Takahiko Hariyama $^{2}$ Yumi Yamahama ${ }^{2} \cdot$ Mina Toyama $^{2} \cdot$ Izumi Ohta $^{1}$
}

Published online: 5 April 2018

(C) The Japanese Society of Applied Entomology and Zoology 2018

\section{Correction to: Applied Entomology Zoology (2018) 53:117-128 https://doi.org/10.1007/s13355-017-0537-5}

Unfortunately, the Table 1 was published incorrectly in the original publication of the article. The correct version of Table 1 is as below,

Table 1 Driving-out effect of red light irradiation on T. palmi present on a plant

\begin{tabular}{|c|c|c|c|c|c|}
\hline \multirow[t]{2}{*}{ Treatment } & \multicolumn{2}{|l|}{ Irradiation from above } & \multirow[t]{2}{*}{ Treatment } & \multicolumn{2}{|c|}{ Irradiation from the side } \\
\hline & No. remaining fixed & No. migrating & & No. remaining fixed & No. migrating \\
\hline IV & $24.5 \pm 1.8^{\mathrm{b}}$ & $1.7 \pm 0.3^{\mathrm{a}}$ & VI & $21.3 \pm 2.1^{\mathrm{b}}$ & $3.2 \pm 1.1^{\mathrm{a}}$ \\
\hline $\mathrm{V}$ & $36.2 \pm 2.5^{\mathrm{a}}$ & $0.0 \pm 0.0^{\mathrm{b}}$ & VII & $30.3 \pm 2.1^{\mathrm{a}}$ & $0.3 \pm 0.2^{b}$ \\
\hline VIII $(1)^{\mathrm{a}}$ & $36.2 \pm 1.5^{\mathrm{a}}$ & $0.2 \pm 0.2^{\mathrm{b}}$ & VIII $(2)^{\mathrm{a}}$ & $36.0 \pm 1.0^{\mathrm{a}}$ & $0.2 \pm 0.2^{b}$ \\
\hline$F$ value & 12.2 & 18.2 & $F$ value & 16.4 & 6.6 \\
\hline$p$ value & $<0.001$ & $<0.0001$ & $p$ value & $<0.001$ & $<0.01$ \\
\hline
\end{tabular}

The number that remained fixed is the number of thrips that remained on the plant on which they were first placed, while the number of migrating individuals is the number that moved to a plant that was originally unoccupied. See Fig. 1 for descriptions of IV to VIII. This experiment was replicated six times for each treatment

${ }^{a}$ For VIII (the control), six replicates were performed twice each as indicated by (1) and (2), because VIII (the control) was conducted simultaneously with IV and V, or VI and VII. Values with the same letter are not significantly different among IV, V and VIII (1), or VI, VII and VIII (2) (Tukey-Kramer honest significant difference test)

The original article can be found online at https://doi.org/10.1007/ s13355-017-0537-5.

\section{Mika Murata}

muratam@affrc.go.jp

1 Division of Vegetable Pest Management and Functional Analysis, Institute of Vegetable and Floriculture Science, NARO (NIVFS), 360 Kusawa, Ano-cho, Tsu, Mie 514-2392, Japan

2 Hamamatsu University School of Medicine, Hamamatsu 431-3192, Japan 